\title{
Psychological and sociological theories concerning adjustment to traumatic spinal cord injury: the implications for rehabilitation
}

\author{
K R Whalley Hammell OT(C) DipCOT \\ Rehabilitation Research Unit, University of Southampton, Southampton General Hospital \\ Southampton SO9 $4 X Y$, England.
}

During the past decades many healthcare professionals have turned their attention to describing the process of adjustment to traumatic spinal cord injury. Extensive review of the literature concerning adjustment is examined, together with an analysis of the effect which these theories have upon the healthcare provider who interacts with the client.

Traditional rehabilitation has had the objective of teaching physical skills to such patients in order to achieve the highest possible level of independence. This paper challenges the rehabilitation team to broaden this concept of successful outcome. 'Living' requires more than physical survival.

Key words: spinal cord injuries; psychological adjustment; sociological adjustment; rehabilitation.

\section{Introduction}

The person with a recent, traumatic severe spinal cord injury (SCI) is predominantly young, male and action oriented. ${ }^{1} \mathrm{He}$ experiences the trauma of one of the most devastating of all non fatal injuries ${ }^{2,3}$ following which, the goal is not that of medical recovery but of adjustment or adaptation to circumstances which have been drastically changed. ${ }^{4}$

The past decades have seen a burgeoning of interest in the process of adjustment to the trauma of spinal cord injury. A great deal has been written, much of it from the observations of professionals. There have been trends in theories and many contradictions. From a review of the literature to 1980, Tucker, ${ }^{5}$ identifies 2 main themes: that emotional adjustment is the key to rehabilitation, and that staff attitudes are crucial to the outcome of rehabilitation. Despite this, discussion of the process of adjustment which is experienced by the spinal cord injured person is frequently neglected in the major texts.

This paper will review some of the extensive literature concerning adjustment to trau-

Correspondence: Box 515, Oxbow, Sask Soc 2BO, Canada. matic spinal cord injury. It will be proposed that these papers have serious implications for healthcare professionals who are involved in the rehabilitation of the person with a spinal cord injury.

\section{Terminology}

The spinal cord injured individual is referred to in the text as 'he'. This is for convenience but does also reflect the large proportion $(82 \%)$ of males who sustain a spinal injury.

As references are used from North America and Great Britain, the term 'quadriplegia' is used interchangeably with 'tetraplegia' to describe involvement of all 4 limbs.

\section{Aspects of rehabilitation}

Expert medical care is essential in the early management of spinal cord injury in order to ensure survival and to prevent unnecessary complications. Once the acute stage has passed however, medicine can offer no cure and it is up to each individual to learn to live with the resulting disability in the context of his own environment.

Traditionally, rehabilitation has been viewed as the teaching of physical skills in 
order to achieve the highest possible level of independence. Success in activities of daily living such as self care, transfers and other physical skills was regarded as being evidence of good rehabilitation. ${ }^{6}$

Two problems arise from this traditional view of what constitutes successful rehabilitation. One concerns those individuals who sustain high level injuries to the cervical spinal cord ( $\mathrm{C} 4$ and above) and who may not be viewed by the healthcare team as having rehabilitation potential. These people may receive little or no help in their process of massive adjustment and learning of new skills, unless a new perspective is taken of rehabilitation. ${ }^{7}$

The other issue which arises is the definition of 'success'. The question which may be posed is whether physical skills alone determine successful reintegration into the community and to adjustment to life in an altered form. Satisfying relationships and a meaningful interaction with the social and physical environment depend upon much more than the ability to transfer and dress independently. ${ }^{8}$ It is proposed therefore, that the aims of the rehabilitation team should not only focus upon the acquisition of skills to enable a person to get out of bed in the morning, but to assist him in finding his own reason for so doing. ${ }^{9}$

\section{Psychological theories}

\section{Crisis and denial}

A traumatic injury to the spinal cord presents a sudden, overwhelming threat to the individual's safety and constitutes a crisis event. At this stage, crisis intervention is directed to survival of the injury-with increasing success. However, the crisis should not be perceived purely in the context of the potential for physical harm to the life of the patient. Parry describes some responses which may result from the reaction of the person to his crisis. There may be short term unreality and anaesthesia; sleep disturbance; disrupted appetite and indigestion; muscle tension; aches, pains, skin rashes, infections; anxiety and depression; problems with reasoning, judgment and concentration; avoidance of the problem; mental preoccupation with the problem; anger, shame and guilt. ${ }^{10}$

Parry's described responses to the trauma or crisis may be exacerbated by the environment and medical interventions being made to manage the crisis. The patient with quadriplegia, for example, has lost sensory impulses from the shoulders down. He cannot feel or move. If he is being treated with tongs on a Stryker frame he will alternate between a view of the ceiling and one of the floor. Two-hourly turns to prevent the formation of pressure sores will certainly tend to disrupt sleep. Pain may be severe. If he has had a tracheostomy, he may be unable to communicate.

Hopkins $^{11}$ states that immediately post trauma the patient denies the problem in order to cope with it. However, Lindh and Rickerson ${ }^{12}$ believe that it is the sensory deprivation which results both from the injury and its management that may produce confusion and disorientation. 'Denial' implies rejection or refusal and may be a more active process than is actually occurring in the early weeks following injury. Horn ${ }^{13}$ expands upon the factors which may keep reality at bay, including medications, severe pain, total immobilisation and enforced bedrest. She proposes that, as a result, this phase may be passed in a dream like state in which adaptation cannot begin and new learning is not able to take place.

Several writers have demanded that 'denial' (or rejection of the fact of the injury) should not be confused with hope, which may be an important concept for both the patient and his family at this time. Trieschmann ${ }^{9}$ believes that despite much speculation, no data has been found which substantiates the idea of 'denial'. In fact, many patients actively seek information concerning the implications of their injury in the early weeks of treatment.

\section{Stage theorists}

Much attention has been focused upon the 'stage theories' concerning adjustment to spinal cord injury. Hohmann ${ }^{14}$ wrote that a 'normal' individual experiences a sequence of attitudes and feelings as he strives to cope with his injury. The stages included in his sequence were denial, withdrawal, hostility 
and reaction against dependence. His subjective observations have been cited elsewhere in the literature and the implication for an individual who does not proceed through the prescribed phases is that he must, by default, be abnormal.

Bracken and Shephard ${ }^{15}$ delineate the following stages: denial, rage and anger, bargaining, depression and, eventually, acceptance. Versluys ${ }^{16}$ also describes distinct phases of adjustment to disability, including 'regression' which is described as a phase in which there is a retreat from standards of adult independence, with more dependence on others and a more infantile level of weakness. This is an interesting theory of a psychological reaction since it so accurately describes the early physical manifestations of the spinal cord injury itself.

The phase theory is accepted in other works, ${ }^{15,17}$ although these studies are based upon the observations of the authors and in general predate more objective analyses of the adjustment process. More recent works have provided evidence that experienced professionals have been 'shown to exaggerate the distress of their SCI patients and these misperceptions tend to worsen progressively with the length of clinical experience'. ${ }^{18}$ There would appear to be dangers in assigning emotions to another person and in regarding people who have sustained a spinal cord injury as being a homogenous group.

Ditunno et $a l^{19}$ present a study which provides evidence that spinal cord injury is not the product of a sensation seeking trait and furthermore that there is no one premorbid personality trait which could distinguish the spinal cord injured population from the normal population. It would thus seem inconceivable that trauma would produce the same response in a heterogeneous group of people.

A review of the recent literature and a follow up study of over 400 patients support the conclusion that there is no one typical personality among people with spinal cord injuries. ${ }^{20}$ Bartol $^{21}$ affirms that 'the only thing spinal cord injured persons have in common is their disability'.

This is not to deny the usefulness of theories. Crewe and Krause ${ }^{22}$ state that many professionals find them useful, suggesting as they do, an orderly and predictable process. 'However, a danger lies in the rigid application of these theories; that is, in attempting to make the person and treatment fit the theory, rather than using the theory as an aid in interpreting observed reactions'.

Kerr and Thompson ${ }^{23}$ wrote a paper which concerned the acceptance of disability of sudden onset in paraplegia in which, from their 'virtual complete agreement', they assign degrees of emotional and social adjustment to their former patients - including before the accident. No mention is made as to how conclusions were drawn concerning pre injury situations and families were not interviewed regarding pre injury personality. Social situation is not easy to assess, especially where there are discrepancies between the ethnic, social and life values of the clients and those of the professionals.

\section{Challenge to stage theories}

In 1980 Trieschmann $^{9}$ published a ground breaking study concerning adjustment to spinal cord injury. This was warmly received by persons who had themselves sustained spinal cord injuries and who had apparently felt victimised by the professionals who had written about reactions to disability that were based less on fact than on theory. Trieschmann ${ }^{1}$ writes that 'the stage theory of adjustment has been discussed by many recognised experts in the field but little empirical evidence has been offered to substantiate the assertions of the theory'.

Silver and Wortman ${ }^{24}$ also challenge the theory by an extensive review of the literature. They suggest that there is a great deal of variability in response to trauma and that little reliable evidence exists which indicates that negative life events produce stages of emotional response.

Shadish, Hickman and Arrick ${ }^{25}$ documented the results of using an assessment scale to evaluate psychological problems. This did not support the belief that there is a uniform emotional stage reaction to spinal cord injury.

Woodbury and Redd ${ }^{26}$ found that 'no single theory of response to crisis or adjust- 
ment to disability seems to account adequately for the total picture of the patient's psychological process'.

Oliver $^{27}$ sees stage theories as a problem, primarily because they 'fail to accord with the personal experiences of many disabled people who may not grieve or mourn or pass through a series of adjustment stages'. He also believes that there are serious questions to be raised concerning whether an individual can be viewed in isolation, rather than as part of a family and social network.

\section{Depression and staff attitudes}

Burke and Murray ${ }^{28}$ adhere to the stage theory of adaptation to injury and stress their belief that depression is an essential component in this process. 'When a newly paralysed person does not seem to be depressed, usually what is happening is a denial of functional loss or its social implications' (page 79). The inherent implication seems to be that not being depressed is abnormal or deviant. They likewise postulate on 'dependency', stating that this is a 'prominent form of adjustment. There are two general types: overdependence and underdependence'. This would seem to imply that there is no balance between these 2 'norms' and that either response is a problem.

Krueger $^{29}$ describes depression as being a normal response to traumatic disability. $\mathrm{He}$ proceeds further to state that if it does not occur, even transiently, an alarm should sound because its absence indicates that the reality of the loss has not been emotionally recognised' (page 9). Viewing depression as a natural and necessary part of the process of adjustment to traumatic injury was common in early literature on the subject.

Goldiamond, who is himself a psychologist and spinal cord injured, wrote the hospital told my wife to expect me to be profoundly depressed. When she protested that I was not depressed, the staff greeted the news with great scepticism'. ${ }^{30} \mathrm{He}$ also quotes the case of a Marine corporal who underwent surgery for removal of a bullet and learned that he would be paralysed for life (Newsweek, March 5 1973). He was not depressed, but happy to be alive at all. 'I adjusted to the fact so quickly', he reported, 'that they sent me to a psychiatrist to find out if I was okay'.

Few clinicians would deny the presence of depression in some spinal cord injured patients. However, this is not the same as ascribing depressive symptoms to every patient and viewing as maladaptive those who do not show evidence of depression.

Recent studies have investigated depression following spinal cord injury. One concludes that the results of their study do not substantiate the earlier observations that depression is experienced by all people with spinal cord injuries. ${ }^{31}$

Cushman and Dijkers ${ }^{32}$ formulated a study to correlate the staff and patient perception of depression. Each day the patient was asked to rank his feelings of depression. His care providers-nurses, doctors, therapists-compiled the same form, indicating their perceptions of his feelings of depression. 'There was a consistent bias on the part of the staff to overestimate depressed mood, relative to the report of the patient themselves'. They believe that staff may hold preconceived ideas concerning the typical response to spinal cord injury and that these ideas then serve to distort what is actually observed. This is consistent with the suggestion 'that patient behaviour is interpreted according to the prevailing professional ideology; in the case of rehabilitation personnel, this view includes depression as a necessary phase of adjustment to SCI' ${ }^{33}$ Conversely, it has been suggested that optimism among paraplegics is not accepted at face value by the staff. ${ }^{18,34}$ Caplan and Shechter ${ }^{35}$ quote a 1977 study (Lawson). 'Many disabled persons have stated that the most "depressing" aspect of their post injury rehabilitation experience was staff members telling them that they should be depressed'.

It was formerly believed that 'adjustment' as a process would not be complete until the person had experienced depression. Trieschmann ${ }^{9}$ states that 'the data suggest the opposite. Recent research tends to suggest that those who are least depressed tend to function best during rehabilitation and following discharge'. Other researchers corroborate the idea that depression appears to 
be counterproductive to post discharge outcome. ${ }^{36,37}$

This raises the issue outlined by Tucker ${ }^{5}$ that staff attitudes are crucial to the outcome of rehabilitation. Bodenhamer et al ${ }^{38}$ agree that among the psychosocial variables which appear to have an important influence upon outcome are the reactions and expectations of the rehabilitation staff.

Bodenhamer et $a l^{38}$ report that their comparisons of results of patient and staff responses to a psychosocial questionnaire for spinal cord injured persons adds support 'to the growing body of evidence that serious discrepancies exist between the perceptions held by rehabilitation personnel of their SCI patients' psychosocial situations and what their patients actually report' (page 191).

\section{Personality theories}

\section{Locus of control}

Rotter ${ }^{39}$ described those people who believe that they have a high degree of personal control over events as having an 'internal locus of control'. In contrast, those people who believe that they have little control over events and situations, who believe instead in luck or fate are defined as having an 'external locus of control'. Frank and Elliott ${ }^{40}$ found that spinal cord injured patients who believe that they are primarily responsible for their health show less depression and more adaptive behaviour than those who have more externalised beliefs.

In a study concerning the relationship between locus of control expectancy and adjustment to traumatic spinal cord injury, Mazzulla ${ }^{41}$ supported the view that those individuals who exhibited an internal locus of control were more able to adjust to the onset of spinal injury. This was irrespective of the time since onset or of the level of disability which determined the actual amount of physical control which the patient could exert. It is noted in Trieschmann ${ }^{8}$ that 'even though a person with quadriplegia may in fact have less control over his immediate circumstances, this does not necessarily change the generalised expectancy of control over the rewards in life nor satisfaction with life'. Mazzulla ${ }^{41}$ emphas- ises that 'the central issue is not the reality of control over reinforcements but the belief of control'.

Further, Nordholm and Westbrook ${ }^{34}$ indicate that one manifestation of the personality trait of internal control may be that of assuming responsibility for, or blaming oneself for the accident which produced the disability. Several writers have suggested that those individuals who assume responsibility for their accidents make better adjustments following discharge than those who perceived themselves as being innocent victims'. ${ }^{8}$

Trieschmann ${ }^{9}$ supports the theory that an internal locus of control is associated with successful rehabilitation outcome but emphasises that it is one of many variables which mitigate for a positive outcome. These include being young, having financial resources, the ability to problem-solve creatively, having many goals and having a warm and loving family background and interpersonal support. The rehabilitation personnel can work with the patient to increase his sense of control over his environment and thus reinforce the belief that control is still a possbility. Early interaction with environmental control units, for example, introduces the opportunity for control to the patient in the acute setting and will continue as the patient is encouraged to participate actively in setting goals and making realistic choices.

Wright ${ }^{42}$ believes that adjustment to disability requires value changes. Not only will the meaning which the individual attaches to disability need to change or be modified but he may also need to change his attitudes about what is meaningful in his life. This view is echoed in the belief that 2 critical features of personality are essential to survival and success following a spinal cord injury. One is the willingness to accept responsibility for one's life. The other, is 'a deep and abiding will to live'. ${ }^{8}$

\section{Maslow's hierarchy of needs}

Maslow defined human needs as existing in a hierarchy. ${ }^{43}$ The hierarchy consists of 5 levels and the theory states that each need level must be satisfied before man can seek 
satisfaction at a higher level. The lowest level is of basic physiological needs and ascends through security, love and belongingness, self esteem and self actualisation.

Starck $^{44}$ studied 25 people with spinal cord injury who were living in the community and ascribed their stated problems to one of Maslow's 5 levels of needs. 'Basic physiologic needs' included such problems as muscle spasticity, soft tissue damage, paralysis, loss of sensation and autonomic hyperreflexia. 'Security' problems included loss of mobility, transportation difficulties, financial insecurity and insecurity concerning long term care. 'Love and belongingness' included problems related to sexual love adjustments, limitations in social activities and limitations in touching. Starck includes frustrations with architectural barriers, discomfort in asking for help and dissatisfaction with education or occupation under 'self esteem'. Problems with 'self actualisation' included lack of spontaneity in life, boredom and dissatisfaction with meaning and purpose in life.

Whilst it appears doubtful that such a neatly delineated model can be usefully applied to an individual person, this listing does provide a challenge to the rehabilitation programme, emphasising the importance of providing support for and attention to every aspect of a person's life.

Richards $^{45}$ studied spinal cord injured patients following discharge from hospital. After analysing his findings, he writes: 'In an age when technologic advances in medicine are ensuring survival of persons who will be severely physically impaired for life, it is comforting to know that such persons as a group are able to adjust to their limitations in a way suggesting that quality of life is, in fact, possible'.

\section{Sociological theories}

Oliver $^{46}$ argues that psychological approaches to adjustment to disability have dominated the field to the comparative neglect of the impact upon family life and upon other family members. He suggests that adjustment to sudden, traumatic spinal cord injury is often more difficult for other family members than for the injured person him- self. Recent literature has acknowledged that the injury has an impact on the whole family. ${ }^{47}$ Richmond $^{48}$ states that 'spinal cord injury occurs not just to the individual but to the entire family'.

Adjustment to spinal cord injury has generally been examined in the literature solely from the viewpoint of the injured person. Little attention has been focused on the family, although several writers stress the importance of strong family support as being a major factor in the process of adjustment. . $^{2,21,26,49-51}$

Oliver et $\mathrm{l}^{51}$ believe that the process of social adjustment arises both from the interactions between the individual and his physical and social environment and, more importantly, from the meanings which these interactions have for both the individual and his family.

Butt $^{50}$ and Trieschmann ${ }^{8}$ proceed from the sociological theory to describe outcome as a complex interactional equation of many factors. Compounding factors include age, intellectual capacity, philosophical religious beliefs, family structure, quality of interpersonal relationships, academic background, previous losses and coping abilities and the symbolic meaning which spinal cord injury has for the individual. Others include medical complications, medications, endurance, strength, coordination, pain and degree of impairment. Environmental variables include income, transportation, architectural and geographical barriers, educational and vocational resources and family and interpersonal support. They feel that the interaction of so many variables will make it impossible to identify a course of adjustment which is predictable, solitary and uniform.

In summary, the sociological theorists examine the adjustment to disability in the broad context of the social environment of each individual. Successful outcome is felt to relate not only to the physical abilities of the patient but also to his unique physical and social environment.

\section{Implications for rehabilitation personnel}

Goldiamond queries the psychological theories to which healthcare personnel have 
tended to adhere. 'Reaction to one's injury is supposed to cause depression. By considering apathy, depression or aggression as inevitable developmental stages in injury ... the professional staff can avoid asking how their actions might have been causal'. ${ }^{30}$ $\mathrm{He}$ believes that rather than listing 'problems' it is more useful to define those problems in terms of goals and then establish ways to achieving those goals. 'When the professional refers to the patient as being "unaware of", "not realistic about" or "repressing" his problem it is often the professional who is being unrealistic ... If a patient does not "face up" to these issues, it may be because he is facing, or trying to face in a different direction, one that can help him achieve his goals'.

Literature which concerns itself with the factors that are involved in the family's reaction to $\mathrm{SCI}$ is conspicuous by its absence. Given the acknowledged role which the family plays in the successful outcome of the rehabilitation process this would appear to be an area which could usefully be researched further.

\section{Compliance and control}

In an article concerning 'powerlessness' in patients with injuries to their cervical spinal cords, Mahon-Darby et $a^{52}$ state that the primary goal of rehabilitation is to 'promote the patient's independent thought and restore a sense of power through self directed behaviour'. They stress that self directed behaviour is a survival skill for the tetraplegic person. This provokes a need to reexamine the goals of treatment to ensure that what is being achieved is independent behaviour, for as Trieschmann ${ }^{8}$ reflects, 'if we implicitly treat the person as the passive recipient of units of therapy in the rehabilitation hospital, how can we expect the person to be an active participant in life outside?' A passive, compliant patient is not then, the most likely to achieve a good outcome.

The concept of 'compliance' encompasses complaisance, yielding and submission. Tucker $^{4}$ reiterates that compliance may not be the most beneficial attribute for a spinal cord injured person upon re-entry to the community. Cooperation with another's goals is not a predictor of independent living. She states, 'the patient who assesses his or her own needs, decides on goals and implements behaviour to meet these goals is considered "demanding" or "resistant". Yet these are the very criteria that Coles ${ }^{53}$ describes as creating the environment in which people learn best. This is relevant, since it has already been stated that rehabilitation is a learning process - learning how to live in one's own environment. Tucker ${ }^{4}$ asserts that staff members should be supportive of goal directed, assertive behaviour.

Frequently, however, rehabilitation staff may communicate conflicting expectations for their patients. Staff members may expect unquestioning compliance, gratitude and passivity from the patient. A contradictory message may also be communicated-that the patient must confront his disability, whilst learning problem solving and independence skills. ${ }^{5}$ Compliance, passivity and cooperation with authority instead tend to foster dependence.

Another writer notes 'that compliance may not always be in the best interests of the disabled person in the long run because compliance with externally imposed routines does not teach independence, problem solving and coping with a disability'. ${ }^{1}$

\section{Model for rehabilitation}

It has been proposed that adjustment to a traumatic spinal cord injury is not an isolated process but one which involves close family and friends. The objectives of the rehabilitation team should therefore include facilitation of the family's adaptation to their changed circumstances. ${ }^{54}$ 'Moreover, by understanding the influential variables related to the acceptance of disability, rehabilitation educators and researchers could design professional training and research programs which would give thorough consideration to the psychological, social and vocational implication of living with a spinal cord disability'. ${ }^{55}$

Planning of a rehabilitation service needs to incorporate flexibility to encourage goal choices by the clients. In the past, the 
rehabilitation staff usually decided what the clients' goals should be. There was also 'an overall prevailing tendency toward adjusting the disabled to the social structure of rehabilitation setting and its requirements rather than the other way round'. ${ }^{56}$

In order to achieve meaningful life and not just physical survival, more than physical skills and a high activities of daily living score must be achieved. Other skills must be acquired, such as creative recreation; financial planning; negotiating community barriers (architectural and interpersonal); social skills training (putting able bodied people at ease); managing an attendant; creative problem-solving; accessing community resources; assertiveness; sexual expression; vocational planning/training; and use of community transportation.

The rehabilitation team will need to become more flexible in recognising the heterogeneity of the life values of the individual. The 'activated' patient is one who asserts early control over his environment and works with the healthcare professionals in establishing realistic goals. This requires cooperation on the part of the staff, not compliance on the part of the patient.

More focus will be upon outpatient services which may assist the spinal cord injured person in finding solutions to problems once these have been identified. Inpatient rehabilitation is an environment ideally suited to learning self care skills. Yet the implications of living in the community with a spinal cord injury can scarcely be anticipated accurately by the newly injured individual or the able bodied staff. Comprehensive outpatient services should ensure that once problems have been identified, the knowledge and skills of professional and client can be combined to focus upon possible choices for action. The lifelong process of adjustment to disability and to interacting with society and the environment is not complete at discharge from an inpatient facility. Rather, this is when true adjustment and adaptation begins.

\section{Discussion}

This study has examined some of the many opinions which professionals have concern- ing adjustment to traumatic spinal cord injury and some comments from those who have themselves made that adjustment. The emphasis throughout has been to require rehabilitation personnel to view each person as an individual and to view rehabilitation itself as a larger concept than merely the teaching of physical skills.

As early as 1968, Hallin stated his belief that psychological adjustment is the critical factor in determining rehabilitation success. ${ }^{57}$ Yet physical and functional goals tend to be the main focus of the rehabilitation process.

Theories are of use in providing a broad framework or guide within which to assess and assist spinal cord injured patients. ${ }^{58}$ However, they should not be viewed as being rigid models to which each person should be made to fit. There needs to be a careful balance between overemphasising the psychological adjustment that the trauma of spinal cord injury necessitates and ignoring it.

In the words of Woodbury and Redd ${ }^{26}$ : '. . . healthcare professionals always need to remain aware that there is no one "right" way to go about adjusting to spinal cord injury. Our job is to facilitate the patient's progress, not dictate it!'

\section{Conclusion}

Society has tended to view traumatic disability as a tragedy, requiring a response of sadness and depression and frequently these attitudes are reflected by healthcare personnel. If the individual breaks out of that mould, he is regarded as being different or special. Sociologists suggest however that, as the majority of people who sustain spinal cord injuries do achieve satisfying and fulfilling lives, this should be regarded as the norm, not the exception. ${ }^{59}$

It is incumbent upon the healthcare professional to facilitate the process of adjustment and to recognise that it is not the injury itself which is the predictor of response but the individual characteristics of the person himself. ${ }^{60}$ This will include to an important extent, their unique personal, social and economic circumstances. ${ }^{61}$

Rehabilitation is a lifelong process. It 
does not cease at discharge and it does not consist purely of learning adeptness at physical skills.

In conclusion, the last word must be given to someone who has personal experience of disability from which to relate the theories and musings of professionals.

'I realised how meagre are our attempts to write and do research about adjustment and adaptation. It would be nice if, at some point, growing up ends and maturity begins, or if one could say that successful adjustment and adaptation to a particular difficulty had been achieved ... problems must be faced, evaluated, re-defined, and re-adapted to again, and again and again'. ${ }^{62}$

\section{Acknowledgement}

Gratitude is extended to Sandra Horn of the University of Southampton Rehabilitation Research Unit for her constructive help with this research.

\section{References}

1 Trieschmann RB (1986) The psychosocial adjustment to spinal cord injury. In: Bloch RF, Basbaum M, editors. Management of Spinal Cord Injuries. Williams and Wilkins, Baltimore.

2 Bingley J (1990) Rehabilitation after spinal cord injury. Nurs Stand 38(4): 27-30.

3 Brackett TO, Condon N, Kindelan K, Bassett I (1984) The emotional care of a person with a spinal cord injury. J Am Med Assoc 252: 793-795.

4 Tucker SJ (1984) Patient and staff interaction with the spinal cord patient. In: Krueger DW, ed. Rehabilitation Psychology Aspen Publishing, Rockville.

5 Tucker SJ (1980) The psychology of spinal cord injury: patient-staff interaction. Rehabil Lit 41(5-6): 114-122.

6 Marshall T (1984) Living a normal life. In: Capildeo R, Maxwell A, editors. Paraplegia. Progress in Rehabilitation series. The Macmillan Press, Basingstoke.

7 Whalley Hammell KR (1991) Occupational therapy in the management of high level quadriplegia. $B r J$ Occup Ther 54(9): 333-340.

8 Trieschmann RB (1988) Spinal Cord Injuries-Psychological, Social and Vocational Rehabilitation, 2nd edition. Demos Publications, New York.

9 Trieschmann RB (1980) Spinal Cord Injuries-Psychological, Social and Vocational Adjustment. Pergamon Press, New York.

10 Parry G (1990) Coping with Crises. The British Psychological Society and Routledge Ltd, London.

11 Hopkins HL (1971) Occupational therapy management of spinal cord injuries-paraplegia and quadriplegia. In: Willard HS, Spackman CS, editors. Occupational Therapy, 4th ed. Lippincott, Philadelphia.

12 Lindh K, Rickerson G (1974) Spinal cord injury: you can make a difference. Nursing 4: 41-45.

13 Horn S (1989) Coping with Bereavement. Thorsons, Wellingborough, Northamptonshire.

14 Hohmann GW (1975) Psychological aspects of treatment and rehabilitation of the spinal cord injured person. Clin Orthop Res 112: 81-88.

15 Bracken MB, Shepard MJ (1980) Coping and adaptation following acute spinal cord injury: a theoretical analysis. Paraplegia 18: 74-85.

16 Versluys H (1983) Psychosocial adjustment to physical disability. In: Trombly C, editor. Occupational Therapy for Physical Dysfunction. 2nd ed. Williams and Wilkins, Baltimore.

17 Donovan WH, Bedbrook Sir G (1982) Comprehensive management of spinal cord injury. Clin Symp 34(2), Ciba.

18 Ernst FA (1987) Contrasting perceptions of distress by research personnel and their spinal cord injured subjects. Am J Phys Med 66(1): 12-15.

19 Ditunno P, McCauley C, Marquette C (1985) Sensation seeking behaviour and the incidence of spinal cord injury. Arch Phys Med Rehabil 66: 152-155.

20 Tunks E, Bahry N, Basbaum M (1986) The resocialisation process after spinal cord injury. In: Bloch RF, Basbaum M, editors. Management of Spinal Cord Injuries. Williams and Wilkins, Baltimore.

21 Bartol G (1978) Psychological needs of the spinal cord injured person. J Neurosci Nurs 10(4): 171-175.

22 Crewe NM, Krause JS (1987) Spinal cord injury: psychological aspects. In: Caplan B, editor. Rehabilitation Psychology Desk Reference. Aspen Publishing, Rockville.

23 Kerr WG, Thompson MA (1972) Acceptance of disability of sudden onset in paraplegia. Paraplegia 10: 94-102.

24 Silver R, Wortman C (1980) Coping with undesirable life events. In: Garber J, Seligman N, editors. Human Helplessness: Theory and Applications. Academic Press, New York.

25 Shadish WR Jr, Hickman D, Arrick MC (1981) Psychological problems of spinal cord injury patients: emotional distress as a function of time and locus of control. J Consult Clin Psychol 49(2): 297.

26 Woodbury B, Redd C (1987) Psychosocial issues and approaches. In: Buchanan, Nawoczenski, editors. Spinal Cord Injury Concepts and Management Approaches. Williams and Wilkins, Baltimore. 
27 Oliver M (1983) Social Work with Disabled People. British Association of Social Workers and Macmilian Education Ltd, Basingstoke.

28 Burke DC, Murray DD (1975) Handbook of Spinal Cord Medicine. The Macmillan Press, Basingstoke.

29 Krueger DW (1984) Issues in emotional rehabilitation. In: Krueger DW, editor. Rehabilitation Psychology. Aspen Publishing, Rockville.

30 Goldiamond I (1973) A diary of self modification. Psychol Today 7: 95-100.

31 Judd F, Stone J, Webber J, Brown D, Burrows G (1989) Depression following spinal cord injury. Br J Psychiatry 154: 668-671.

32 Cushman L, Dijkers M (1990) Depressed mood in spinal cord injured patients: staff perceptions and patient realities. Arch Phys Med Rehabil 71: 191-196.

33 Scott RA (1970) The construction of concepts of stigma by professional experts. In: Douglas JD, editor. Deviance and Respectability: The Social Construction of Moral Meanings. Basic Books, New York.

34 Nordholm L, Westbrook M (1986) Effects of depression, self-blame and dependency on health professionals' evaluation of paraplegic patients. Aust Occup Ther J 33(2): 59-70.

35 Caplan B, Shechter J (1987) Denial and depression in disabling illness. Caplan B, editor. In: Rehabilitation Psychology Desk Reference, Aspen Publishing, Rockville.

36 Frank RG, Elliott TR, Corcoran JR, Wonderlich SA (1987) Depression after spinal cord injury: is it necessary? Clin Psychol Rev 7: 611-630.

37 Lawson NC (1978) Significant events in the rehabilitation process: the spinal cord patient's point of view. Arch Phys Med Rehabil 59: 573-579.

38 Bodenhamer E, Achterberg-Lawlis J, Keverkian G, Belanus A, Cofer J (1983) Staff and patient perceptions of the psychosocial concerns of spinal cord injured persons. Am J Phys Med Rehabil 62(4): $182-193$

39 Rotter JB (1966) Generalised expectancies for internal versus external locus of control of reinforcement. Psychology Monograph 80: 1-28.

40 Frank RG, Elliott TR (1989) Spinal cord injury and health locus of control beliefs. Paraplegia 27: $250-256$.

41 Mazzulla JR (1984) Relationship between locus of control expectancy and acceptance of acquired traumatic spinal cord injury. Am Arch Rehabil Ther Winter: 10-13.

42 Wright BA (1983) Physical Disability - A Psychosocial Approach. 2nd ed. Harper and Row, New York.

43 Maslow AH (1970) Motivation and Personality. Harper and Row, New York.

44 Starck PL (1980) Maslow's needs and the spinal cord injured client. Assoc Rehabil Nurs Sep-Oct: 17-20.

45 Richards JS (1986) Psychologic adjustment to spinal cord injury during first post discharge year. Arch Phys Med Rehabil 67: 362-365.

46 Oliver M (1981) Disability, adjustment and family life-some theoretical considerations. In: Brechin A, Liddiard P, Swain J, editors. Handicap in a Social World. Open University Press and Hodder and Stoughton, London.

47 Solursh DS (1990) The family of the trauma victim. Nurs Clin N Am 25(1): 155-162.

48 Richmond TS (1990) Spinal cord injury. Nurs Clin N Am 25(1): 57-70.

49 Donovan WH and Dwyer (1984) Early Management of Traumatic Paraplegia.

50 Butt L (1989) Psychological aspects of discharge. In: Whiteneck G, Adler C, Carter RE, Lammertse DP, Manley S, Menter R et al, editors. The Management of High Level Quadriplegia. Demos Publications New York.

51 Oliver M, Zarb G, Sliver J, Moore M, Salisbury V (1988) Walking into Darkness: The Experience of Spinal Cord Injury. The Macmillan Press, Basingstoke.

52 Mahon-Darby J, Ketchik-Renshaw B, Richmond TS, Gates EM (1988) Powerlessness in cervical spinal cord injury patients. Dimens Crit Care Nurs 7(6): 346-355.

53 Coles C (1989) Self assessment and medical audit: an educational approach. $\mathrm{Br}$ Med J 299: 807-8.

54 Judd FK, Brown DJ (1988) The psychosocial approach to rehabilitation of the spinal cord injured patient. Paraplegia 26: 419-424.

55 Woodrich F, Patterson JB (1983) Variables related to acceptance of disability in persons with spinal cord injuries. J Rehabil 3: 26-30.

56 Safilios-Rothschild C (1970) The Sociology and Social Psychology of Disability and Rehabilitation. Random House, New York.

57 Hallin RP (1968) Follow up of paraplegics and tetraplegics after comprehensive rehabilitation. Int $J$ Paraplegia 6: 128-134.

58 Shontz FC (1978) Psychological adjustment to physical disability: trends in theories. Arch Phys Med Rehabil 59: 251-254.

59 Shearer A (1981) Disability: Whose Handicap? Blackwell, Oxford.

60 Frank RG, Umlauf RL, Wonderlich SA, Askanazi GS, Buckelew SP, Elliott TR (1987) Differences in coping styles among persons with spinal cord injury: a cluster analytic approach. J Consult Clin Psychol 55(5): 727-731.

61 Harris P, Patel SS, Greer W, Naughton JAL (1973) Psychological and social reactions to acute spinal paralysis. Paraplegia 11: 132-136.

62 Zola IK (1982) Missing Pieces: A Chronicle of Living with a Disability. Temple University Press, Philadelphia. 